\title{
Structural Rietveld Refinement of Nickel Ferrite Nanoparticles Prepared by Chemical Method
}

\author{
Y.B. Kannan* \\ Department of Physics, A.P.S.A College, Tiruppattur - 630 211, Tamilnadu, India.
}

\section{ARTICLE DETAILS}

Article history:

Received 25 March 2019

Accepted 18 April 2019

Available online 05 May 2019

Keywords:

Chemical Reaction Method

Spinel Ferrites

Rietveld Analysis

\begin{abstract}
A B S T R A C T
$\mathrm{NiFe}_{2} \mathrm{O}_{4}$ nanoparticles were prepared by chemical reaction method and structural, optical and magnetic properties of nickel ferrite nanoparticles were studied. Rietveld analysis was carried out to determine the experimental lattice parameter and that value agreed well with the theoretical lattice parameter estimated from Nelson-Riley method. Presence of porosity and agglomeration of the particles in the prepared sample can be seen from the SEM image. Optical and magnetic studies were also carried out on the $\mathrm{NiFe}_{2} \mathrm{O}_{4}$ nanoparticles.
\end{abstract}

\section{Introduction}

Magnetic nanoparticles, for the past few decades, have been studied intensively for its extensive applications in the fields of communication, electronic and medical diagnosis [1]. Spinel ferrites, with general formula $(\mathrm{A})\left[\mathrm{B}_{2}\right] \mathrm{O}_{4}$ where $\mathrm{A}$ and $\mathrm{B}$ are respectively divalent and trivalent ions; round brackets ( ) and square brackets [ ] represent tetrahedral (A) and octahedral (B) sites respectively, have numerous applications in technological fields such as magnetic refrigeration, ferrofluids making, magnetic resonance imaging (MRI), information storage, etc., [2-4]. Among the spinel ferrites, nickel ferrite nanoparticles belong to the class of inverse spinel in which the trivalent atoms are equally distributed between tetrahedral and octahedral sites in the unit cell of ferrites. Nickel and substituted nickel ferrite are one of the versatile and technologically important soft ferrite materials because of its typical ferromagnetic properties, low conductivity and thus lower eddy current losses, high electrochemical stability, catalytic behaviour, abundance in nature, etc., [5]. In literature, though various preparation methods are reported [2, 69] chemical reaction method [10] is chosen to prepare $\mathrm{NiFe}_{2} \mathrm{O}_{4}$ nanoparticles because of its high yielding and low-cost route. Structural, optical and magnetic properties of nickel ferrite nanoparticles are reported in this communication.

\section{Experimental Methods}

\subsection{Sample Preparation}

Nickel ferrite nanoparticles were prepared by chemical reaction method. Analytical grade nickel sulphate $\left(\mathrm{NiSO}_{4} \cdot 6 \mathrm{H}_{2} \mathrm{O}\right)$ from Otto chemicals, iron nitrate $\left(\mathrm{Fe}\left(\mathrm{NO}_{3}\right)_{3} .9 \mathrm{H}_{2} \mathrm{O}\right)$ from Loba chemicals, sodium hydroxide $(\mathrm{NaOH})$ and sodium chloride $(\mathrm{NaCl})$ from Alpha Aeser chemicals were used to prepare the sample. The molar ratio is $1: 2: 8: 10$ respectively for the chemicals $\mathrm{NiSO}_{4} \cdot 6 \mathrm{H}_{2} \mathrm{O}, \mathrm{Fe}\left(\mathrm{NO}_{3}\right)_{3} .9 \mathrm{H}_{2} \mathrm{O}, \mathrm{NaOH}$ and $\mathrm{NaCl}$ to prepare the nickel ferrite nanoparticles. These chemicals were taken in an agate mortar pestle and ground together for about 60 minutes. The reaction took place exothermally and the color changed from greenish red to brown during this mixing process. This mixture was subjected to calcination at $700{ }^{\circ} \mathrm{C}$ for 60 minutes. The powder was crushed and then washed with deionized water to remove sodium chloride and dried at 100 ${ }^{\circ} \mathrm{C}$ for 60 minutes to obtain the polycrystalline nickel ferrite nanoparticles.

\subsection{Characterization Techniques}

$\mathrm{X}$-ray diffraction pattern of the sample was recorded at room temperature using Bruker AXS D8 advance X-ray diffractometer with $\mathrm{Cu}$ radiation $(\lambda=1.5406 \AA)$. The sample was exposed to the radiation with a primary beam power of $40 \mathrm{kV}$ and $35 \mathrm{~mA}$ with step scan $0.02^{\circ}$ in $2 \theta$ range from $20^{\circ}-70^{\circ}$. Optical absorption spectra of the samples were recorded in the UV-VIS wavelength range of $2000-7500 \AA$. The magnetic properties of the samples were studied at room temperature by using vibrating sample magnetometer (Lakeshore VSM 7410 Model).

\section{Results and Discussion}

\subsection{XRD Analysis}

X-ray diffraction analysis of the nickel ferrite nanoparticles were collected at room temperature and the raw XRD is shown in the Fig. 1. The peaks in the raw XRD are compared with that in JCPDS file no.86-2267. The presence of the peaks (220), (311), (222), (400), (333)/(511) and (440) in the raw XRD (Fig. 1) confirm the formation of spinel structure with Fd-3m (227) space group. Absence of any additional phases indicates the purity of the prepared sample.

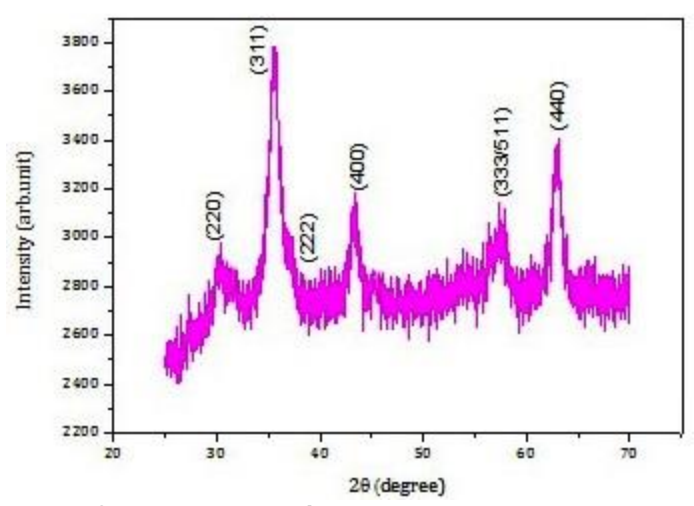

Fig. 1 Raw XRD of $\mathrm{NiFe}_{2} \mathrm{O}_{4}$ nanoparticles

The formation of the cubic spinel structure in the prepared ferrite sample is further confirmed by refining the raw XRD using Rietveld method [11]. Rietveld method [11] is employed for refining the background, pseudo-voigt, asymmetry, preferred orientation, scale and lattice parameters using the software JANA 2006 [12]. Various possible combinations, with constraints on the occupation of cations at the 
tetrahedral (A) and octahedral sites (B), of cation distributions at the A and $B$ sites for the refinement of the raw XRD using Rietveld method [11], were tried out. Among all the possible combinations, the particular combination which has the close agreement between the observed structure factor $\left(\mathrm{F}_{0}\right)$ and calculated structure factor $\left(\mathrm{F}_{\mathrm{C}}\right)$ (Table 1$)$ is considered as the cation distribution at the A and B sites in the prepared sample and is tabulated in Table 2. The cation distribution (Table 2) is considered as occupancy parameter value while refining the sample using Rietveld method [11] using JANA software [12].

Table 1 Observed structure factor $\left(\mathrm{F}_{0}\right)$ and calculated structure factor $\left(\mathrm{F}_{\mathrm{c}}\right)$

\begin{tabular}{lllll}
\hline $\mathrm{h}$ & $\mathrm{k}$ & $\mathrm{l}$ & $\mathrm{F}_{\mathrm{o}}$ & $\mathrm{F}_{\mathrm{c}}$ \\
\hline 2 & 0 & 2 & 137.25 & 155.46 \\
1 & 1 & 3 & 240.85 & 241.00 \\
2 & 2 & 2 & 113.29 & 119.56 \\
0 & 0 & 4 & 240.38 & 244.23 \\
3 & 3 & 3 & 168.86 & 197.12 \\
1 & 1 & 5 & 109.12 & 127.39 \\
4 & 0 & 4 & 311.42 & 318.35 \\
\hline
\end{tabular}

Table 2 Distribution of cations at $\mathrm{A}$ and B-site in the unit cell of $\mathrm{NiFe}_{2} \mathrm{O}_{4}$ nanoparticles

\begin{tabular}{lllll}
\hline \multirow{2}{*}{ Sample } & \multicolumn{2}{l}{ Tetrahedral (A) site } & \multicolumn{2}{l}{ Octahedral (B) site } \\
\cline { 2 - 5 } & $\mathrm{Ni}$ & $\mathrm{Fe}$ & $\mathrm{Ni}$ & $\mathrm{Fe}$ \\
\hline $\mathrm{NiFe}_{2} \mathrm{O}_{4}$ & 0.01 & 0.99 & 0.99 & 1.01 \\
\hline
\end{tabular}

The fitted powder XRD profile of the $\mathrm{NiFe}_{2} \mathrm{O}_{4}$ sample is shown in Fig. 2 and all the structural parameters along with the reliability indices on Rietveld refinements are tabulated in Table 3 . The lattice parameter value (aexp) is found out to be $8.331 \AA$. Theoretically, the lattice parameter value (atheo) is also evaluated using the Nelson-Riley procedure [13] and it is given in the Fig. 3.

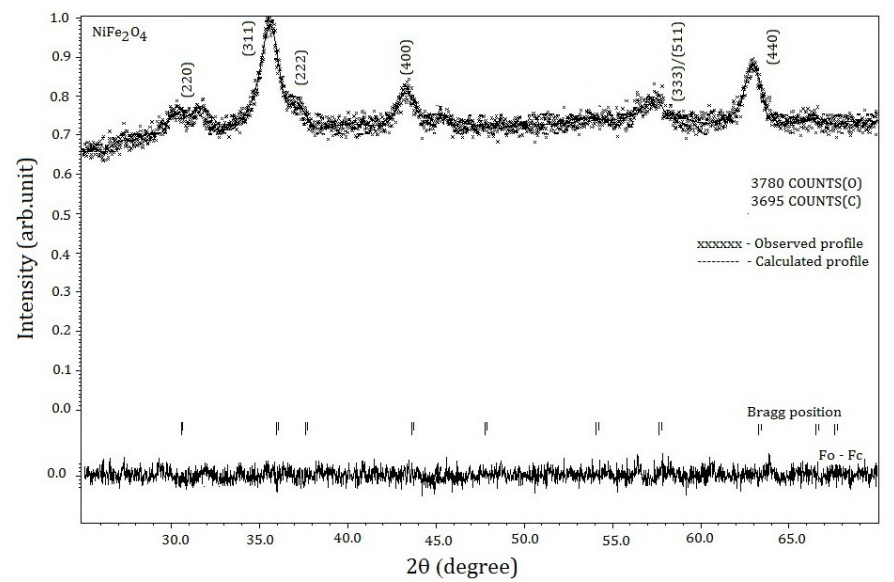

Fig. 2 Fitted powder profile of $\mathrm{NiFe}_{2} \mathrm{O}_{4}$ nanoparticles

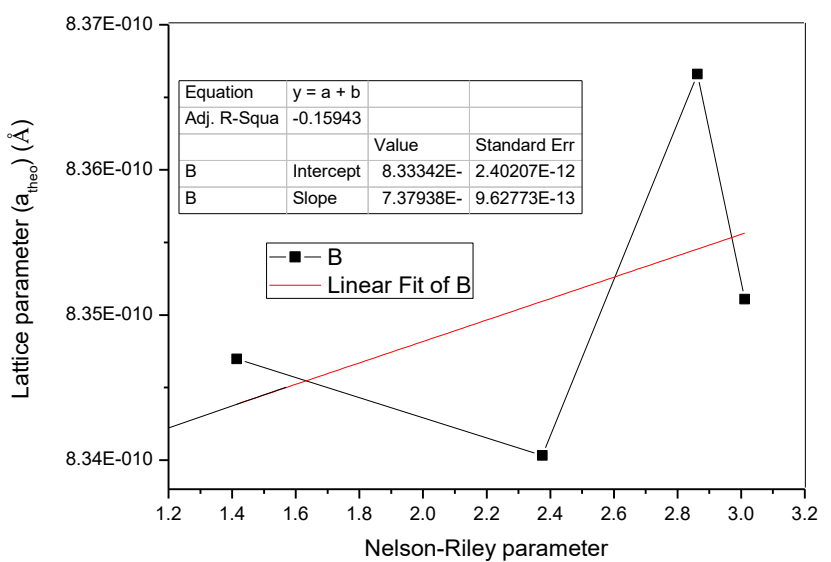

Fig. 3 Nelson-Riley plot to determine the theoretical lattice parameter a(theo) of $\mathrm{NiFe}_{2} \mathrm{O}_{4}$ nanoparticles

The close agreement between the aexp and atheo validates the cation distribution in the prepared sample. Tetrahedral radius $\left(\mathrm{r}_{\mathrm{A}}\right)$ and octahedral radius $\left(\mathrm{r}_{\mathrm{B}}\right)$ can be calculated from the knowledge of cation distribution and also from the XRD data. The values of $r_{A}$ and $r_{B}$ are calculated using the relation [14] and are tabulated in Table 3. The hopping length $\left(\mathrm{L}_{\mathrm{A}}\right.$ and $\mathrm{L}_{B}$ ) between magnetic ions (the distance between the ions) in the tetrahedral A-site and octahedral B-site, various interionic https://doi.org/10.30799/jnst.223.19050202 distances i.e., tetrahedral and octahedral bond length $\mathrm{d}_{\mathrm{AL}}$ and $\mathrm{d}_{\mathrm{BL}}$ tetrahedral edge, shared and unshared octahedral edge $\left(\mathrm{d}_{\mathrm{AE}}, \mathrm{d}_{\mathrm{BE}}\right.$ and $\left.\mathrm{d}_{\mathrm{BEU}}\right)$ are calculated using the relations reported in [15] and the values are listed in Table 3. Presence of porosity and agglomeration of particles can be seen from the SEM images as shown in the Fig. 4. The hkl planes (311), (400) and (440) were used to calculate the average particle size ' $t$ ' using Scherrer formula [14],

$$
\mathrm{t}=\frac{0.9 \lambda}{\beta \cos \theta}
$$

and the value of ' $t$ ' is found out to be 7(1) nm. The average particle size ( $\mathrm{t}_{\text {SEM }}$ ) from the SEM measurement is found out to be $1 \mu \mathrm{m}$. The results revealed that the particle size ( $\left.\mathrm{t}_{\text {SEM }}\right)$ determined by SEM is larger than that $(\mathrm{t})$ obtained from XRD measurements. Since the powder XRD gives only the size of the coherently diffracting domains it cannot be directly compared to the size obtained using an SEM except in rare cases.

Table 3 Rietveld refined structural parameters of $\mathrm{NiFe}_{2} \mathrm{O}_{4}$ nanoparticles

\begin{tabular}{|c|c|c|}
\hline \multicolumn{2}{|l|}{ Parameters } & Value \\
\hline \multirow[t]{2}{*}{ Lattice parameter } & Theoretical $\mathrm{a}_{\text {th }}(\AA)$ & 8.333 \\
\hline & Experimental $\mathrm{a}(\AA)$ & $8.331(4)$ \\
\hline Oxygen positional parameter & 'u' (̊) & $0.384(4)$ \\
\hline \multirow[t]{2}{*}{ Radius of tetrahedral site $r_{A}(\AA)$} & From cation distribution & 0.641 \\
\hline & From XRD & 0.621 \\
\hline \multirow[t]{2}{*}{ Radius of octahedral site $r_{B}(\AA)$} & From cation distribution & 0.665 \\
\hline & From XRD & 0.685 \\
\hline \multicolumn{2}{|l|}{ Tetrahedral bond length $d_{\mathrm{AL}}(\AA)$} & 1.941 \\
\hline \multicolumn{2}{|l|}{ Octahderal bond length $d_{B L}(\AA)$} & 2.006 \\
\hline \multicolumn{2}{|c|}{ Tetrahedral shared edge length $d_{\mathrm{AE}}(\AA)$} & 3.170 \\
\hline \multicolumn{2}{|c|}{ Octahedral shared edge length $\mathrm{d}_{\mathrm{BE}}(\AA)$} & 2.720 \\
\hline \multicolumn{2}{|c|}{ Octahedral unshared edge length $d_{\mathrm{BEU}}(\AA)$} & 2.949 \\
\hline \multicolumn{2}{|c|}{ Hopping length between magnetic ions at $A$-site $L_{A}(\AA)$} & 3.610 \\
\hline \multicolumn{2}{|c|}{ Hopping length between magnetic ions at B-site $L_{B}(\AA)$} & 2.945 \\
\hline \multicolumn{2}{|l|}{$\mathrm{F}_{000}$ (No. electrons in the unit cell) } & 896 \\
\hline \multicolumn{3}{|l|}{ Reliability indices } \\
\hline \multicolumn{2}{|l|}{ Robs (\%) } & 6.20 \\
\hline \multicolumn{2}{|l|}{$w \mathrm{R}_{\mathrm{obs}}(\%)$} & 6.07 \\
\hline \multicolumn{2}{|l|}{$\mathrm{R}_{\mathrm{p}}(\%)$} & 1.82 \\
\hline \multicolumn{2}{|l|}{$w \mathrm{R}_{\mathrm{p}}(\%)$} & 2.54 \\
\hline \multicolumn{2}{|l|}{ GOF } & 1.36 \\
\hline
\end{tabular}

$R_{\text {obs }}=$ Reliability index, $w R_{\text {obs }}=$ Weighted reliability index, $R_{p}=$ Profile reliability index ${ }_{w} R_{p}=$ Weighted profile reliability index, GOF $=$ Goodness of fit

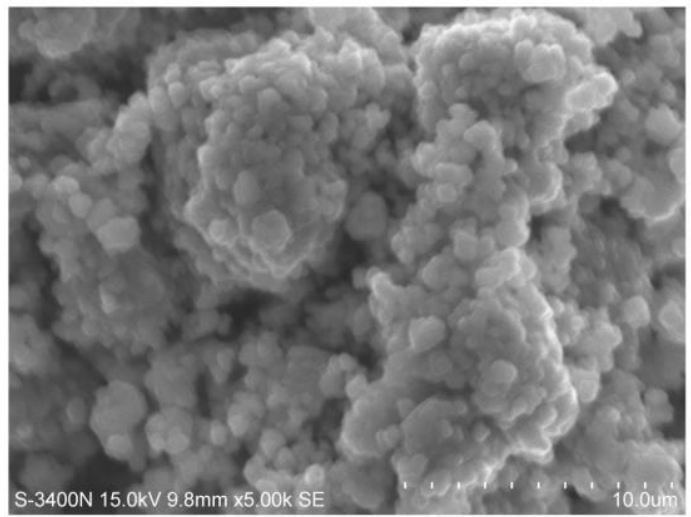

Fig. 4 SEM image of $\mathrm{NiFe}_{2} \mathrm{O}_{4}$ nanoparticles

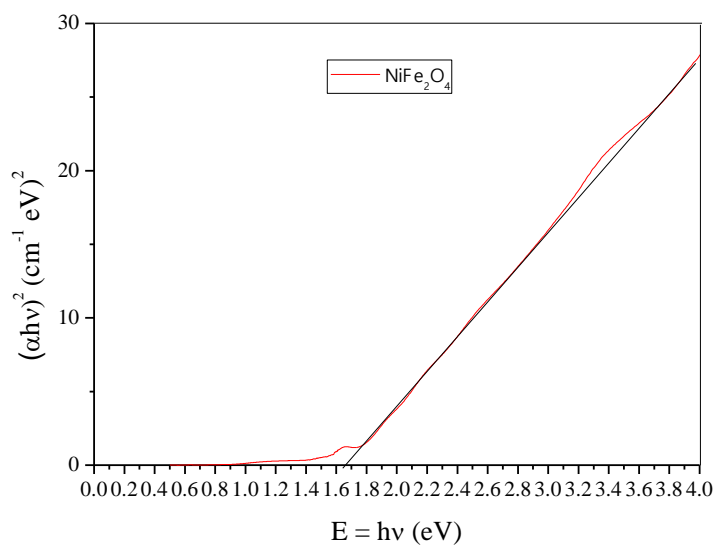

Fig. 5 band gap energy value of $\mathrm{NiFe}_{2} \mathrm{O}_{4}$ nanoparticles 


\subsection{Band Gap Energy Value from UV-Vis Analysis}

Band gap energy value of the $\mathrm{NiFe}_{2} \mathrm{O}_{4}$ nanoparticles were calculated using the Tauc relation $[16,17](\alpha h v)^{2}=A\left(h v-E_{g}\right), \alpha$ is the absorption coefficient, $h v$ is the energy of the incident photon, $A$ is proportionality constant, and $\mathrm{Eg}_{\mathrm{g}}$ is the band gap energy. The linear interpolation of photon energy $(h v)$ against $(\alpha h v)^{2}$ gives the band gap energy and in this present study the value of band gap energy (Fig. 5) is found out to be $1.65 \mathrm{eV}$. Band gap energy values in the range of 1.43 to $1.78 \mathrm{eV}$ for $\mathrm{NiFe}_{2} \mathrm{O}_{4}$ are reported by Manisha Dhiman et al., [18].

\subsection{Magnetic Analysis}

Nickel ferrite nanoparticles were subjected to a maximum applied magnetic field of $20 \mathrm{kG}$ to record the magnetic data at room temperature using a vibrating sample magnetometer. The hysteresis loop, which shows the variation of magnetization as a function of an applied magnetic field is shown in Fig. 6. Saturation magnetization (Ms), coercivity (Hci), retentivity (Mr), squareness ratio (Mr/Ms), Bohr magneton value (both calculated and observed) and the Yaffet-Kittel angle $\left(\theta_{Y \mathrm{~K}}\right)$ of the nickel ferrite sample were calculated from the hysteresis loop and tabulated in Table 4.

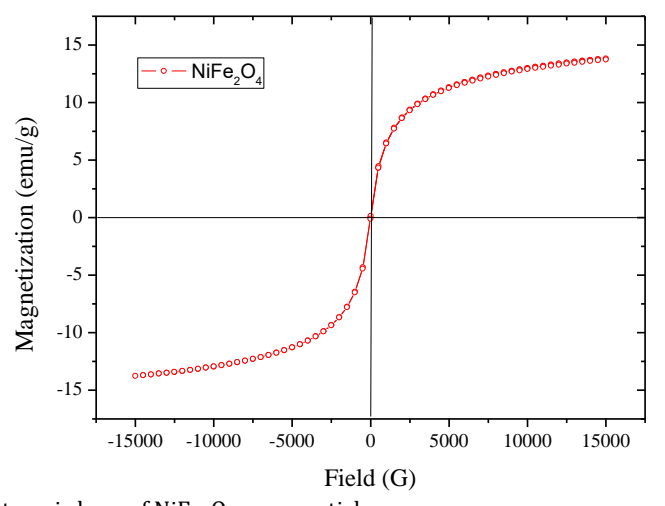

Fig. 6 Hysteresis loop of $\mathrm{NiFe}_{2} \mathrm{O}_{4}$ nanoparticles

Table 4 Magnetic parameters of $\mathrm{NiFe}_{2} \mathrm{O}_{4}$ nanoparticles

\begin{tabular}{|c|c|}
\hline Parameters & Value \\
\hline Saturation Magnetization $M_{S}(\mathrm{emu} / \mathrm{g})$ & 13.80 \\
\hline Coercivity $\left(H_{C i}\right) \mathrm{G}$ & 10.78 \\
\hline Retentivity $\left(M_{r}\right)(\mathrm{emu} / \mathrm{g})$ & 96 \\
\hline Bohr Magneton & 0.58 \\
\hline$\mu_{B}^{N}$ (From cation distribution) & 2.06 \\
\hline Yaffet-Kittel angle $\left({ }^{\circ}\right)$ & 38 \\
\hline Permeability $\mu(\mathrm{emu} / \mathrm{gkOe})$ & 0.709 \\
\hline Squareness $\left(\mathrm{M}_{\mathrm{r}} / \mathrm{M}_{\mathrm{s}}\right)$ & 6.96 \\
\hline
\end{tabular}

The ' $\mathrm{S}$ ' shape of the hysteresis curve together with a small coercivity value reveals the presence of small magnetic particles exhibiting super paramagnetic behavior. The saturation magnetization (Ms) value of nickel ferrite sample at $300 \mathrm{~K}$ is $13.8 \mathrm{emu} / \mathrm{g}$. It is much lower when compared with that of reported value, $55 \mathrm{emu} / \mathrm{g}$ [19] and this is attributed to (i) the core shell morphology of the nanoparticles consisting of ferrimagnetically aligned core spins and spin-glass-like surface layer [20] and (ii) the lower degree of crystalline of the sample [21]. The spin glass shell leads to decrease of the number of an aligned magnetic moment in the entire particle and in the present study this fact is reflected in the discrepancies between Bohr magneton calculated and observed value and the intensity of the (311) peak reflects the lower degree of crystallinity of the sample. The Bohr Magneton value (saturation magnetization per formula unit in Bohr magneton at absolute temperature) evaluated from the hysteresis loop is given by,

$$
\mu_{B}^{H}(\text { Bohr Magneton })=\left\{\frac{\text { molecular weight }}{5585}\right\} \mathrm{M}_{\mathrm{s}}\left(\frac{\text { emu }}{g}\right)
$$

The value of Bohr Magneton calculated on the basis of the cation distribution and the Neel's two sublattice model, i.e. Neel's moment $\mu_{B}^{C a l}=$
$M_{B}-M_{A}$ (where $\mathrm{M}_{\mathrm{B}}$ and $\mathrm{M}_{\mathrm{A}}$ are sublattice magnetizations) for the sample is listed in Table 4 . Due to the discrepancy between $\mu_{B}^{\mathrm{H}}$ and $\mu_{B}^{\mathrm{Cal}}$ values of the Bohr magneton, Neel two sub-lattice model cannot be used in this case. Hence, the Yaffet-Kittel $\left(\theta_{Y K}\right)$ angle is calculated using the relation $\mu_{\mathrm{B}}^{\mathrm{H}}$ $=\mathrm{M}_{\mathrm{B}} \cos \left(\theta_{Y K}\right)-\mathrm{M}_{\mathrm{A}}$. According to the Yaffet-Kittel model, the B sublattice can be split into two sublattices $B_{1}$ and $B_{2}$ having moments equal in magnitude and each making an angle $\left(\theta_{Y K}\right)$ with the direction of the net magnetization at $0 \mathrm{~K}$.

\section{Conclusion}

XRD data of the nickel ferrite sample prepared by chemical reaction method is refined using the Rietveld refinement method. Cation distribution in the unit cell of the prepared sample is confirmed by the close agreement between the theoretical and experimental lattice parameter values. Porous nature of the sample is revealed by the scanning electron microscope image. The magnetic measurement reveals that the sample has low value of saturation magnetization and the presence of Yaffter-Kittel angle.

\section{References}

[1] U. Kurtan, H. Güngünes, H. Sözeri, A. Baykal, Synthesis and characterization of monodisperse $\mathrm{NiFe}_{2} \mathrm{O}_{4}$ nanoparticles, Ceram. Int. 42 (7) (2016) 7987-7992.

[2] Ying Zhang, Gaurab Rimal, Jinke Tang, Qilin Dai, Synthesis of $\mathrm{NiFe}_{2} \mathrm{O}_{4}$ nanoparticles for energy and environment applications, Mater. Res. Express 5(2) (2018) 025023-025030.

[3] P. Sivakumar, R. Ramesh, A. Ramanand, S. Ponnusamy, C. Muthamizhchelvan, Preparation and properties of nickel ferrite $\left(\mathrm{NiFe}_{2} \mathrm{O}_{4}\right)$ nanoparticles via sol-gel auto-combustion method, Mater. Res. Bull. 46 (2011) 2204-2207.

[4] P. Sivakumar, R. Ramesh, A. Ramanand, S. Ponnusamy, C. Muthamizhchelvan Synthesis and characterization of $\mathrm{NiFe}_{2} \mathrm{O}_{4}$ nanoparticles and nanorods, J. Alloy Compd. 563 (2013) 6-11.

[5] Sagar E. Shirsath, B.G. Toksha, K.M. Jadhav, Structural and magnetic properties of In ${ }^{3+}$ substituted $\mathrm{NiFe}_{2} \mathrm{O}_{4}$, Mater. Chem. Phys. 117 (2009) 163-168.

[6] S.V. Bhosale, N.S. Kanhe, S.V. Bhoraskar, S.K. Bhat, R.N. Bulakhe, et al., Microstructural analysis of $\mathrm{NiFe}_{2} \mathrm{O}_{4}$ nanoparticles synthesized by thermal plasma route and its suitability for BSA adsorption, J. Mater. Sci.: Mater. Med. 26 (2015) 216-1-15.

[7] E. Agouriane, A. Essoumhi, A. Razouk, M. Sahlaoui, M. Sajieddine, X-ray diffraction and Mössbauer studies of $\mathrm{NiFe}_{2} \mathrm{O}_{4}$ nanoparticles obtained by coprecipitation method, J. Mater. Environ. Sci. 7(12) (2016) 4614-4619.

[8] Subarna Mitra, Kalyan Mandal, Superparamagnetic behavior in noninteracting $\mathrm{NiFe}_{2} \mathrm{O}_{4}$ nanoparticles grown in $\mathrm{SiO}_{2}$ matrix, Mater. Manuf. Proc. 22 (2007) 444-449.

[9] Shuai Liu, Fang He, Zhen Huang, Anqing Zheng, Yipeng Feng, et al., Screening of $\mathrm{NiFe}_{2} \mathrm{O}_{4}$ nanoparticles as oxygen carrier in chemical looping hydrogen production, Energy Fuels 30(5) (2016) 4251-4262.

[10] L. Darshane Sonali, G. Deshmukh, Rupali, S. Suryavanshi, Shankar, et al., Gassensing properties of zinc ferrite nanoparticles synthesized by the molten-salt route, J. Am. Ceram. Soc. 91(8) (2008) 2724-2726.

[11] H.M. Rietveld, A profile refinement method for nuclear and magnetic, J. Appl. Crystallogr. 2 (1969) 65-71.

[12] V. Petricek, M. Dusek, L. Palatinus, The crystallographic computing system Institute of Physics, Praha, Czech Republic, 2006.

[13] A. Rajabi, M.J. Ghazali, Quantitative analyses of TiC nanopowders via mechanical alloying method, Ceram. Int. 43(16) (2017) 14233-14243.

[14] Y.B. Kannan, R. Saravanan, N. Srinivasan, I. Ismail, Sintering effect on structural, magnetic and optical properties of $\mathrm{Ni}_{0.5} \mathrm{Zn}_{0.5} \mathrm{Fe}_{2} \mathrm{O}_{4}$ ferrite nanoparticles, J. Magn. Magn. Mater. 423 (2017) 217-225.

[15] K. Vijaya Babu, G. Satyanarayana, B. Sailaja, G.V. Santosh Kumar, K. Jalaiah, M. Ravi, Structural and magnetic properties of $\mathrm{Ni}_{0.8} \mathrm{M}_{0.2} \mathrm{Fe}_{2} \mathrm{O}_{4}(\mathrm{M}=\mathrm{Cu}, \mathrm{Co})$ nanocrystalline ferrites, Results Phys. 9 (2018) 55-62

[16] J. Tauc, R. Grigorovic, A. Vancu, Optical properties and electronic structure of amorphous germanium, Phys. Status Solidi B 15 (1966) 627-637.

[17] J. Pancove, Optical process in semiconductors, Englewood Cliffs, Prentice-Hall, NJ, USA, 1971.

[18] Manisha Dhimana, Ankita Goyala, Vinod Kumarb, Sonal Singhal, Designing different morphologies of $\mathrm{NiFe}_{2} \mathrm{O}_{4}$ for tuning of structural, optical and magnetic properties for catalytic advancements, New J. Chem. 40 (2016) 10418-10431.

[19] A. Goldman, Modern ferrites technology, Springer, New York, 2006.

[20] G. Nabiyouni, M. Jafari Fesharaki, M. Mozafari, J. Amighian, Characterization and magnetic properties of nickel ferrite nanoparticles prepared by ball milling technique, Chin. Phys. Lett. 27 (2010) 12640-12644.

[21] J. Azadmanjiri, S.A. Seyyed Ebrahimi, H.K. Salehani, Magnetic properties of nanosize $\mathrm{NiFe}_{2} \mathrm{O}_{4}$ particles synthesized by sol-gel auto combustion method, Ceram. Int. 33 (2007) 1623-1625. 